\title{
Commentary: Work in progress-Defining optimal surgical prehabilitation before lung resection
}

\author{
Erin M. Corsini, MD, and Mara B. Antonoff, MD
}

\footnotetext{
From the Department of Thoracic and Cardiovascular Surgery, The University of Texas MD Anderson Cancer Center, Houston, Tex.

Disclosures: Authors have nothing to disclose with regard to commercial support.

Received for publication Oct 7, 2019; revisions received Oct 7, 2019; accepted for publication Oct 7, 2019; available ahead of print Oct 16, 2019.

Address for reprints: Mara B. Antonoff, MD, Department of Thoracic and Cardiovascular Surgery, University of Texas MD Anderson Cancer Center, 1515 Holcombe Blvd, Houston, TX 77030 (E-mail: MBAntonoff@ mdanderson.org).

J Thorac Cardiovasc Surg 2020;160:1060-1

$0022-5223 / \$ 36.00$

Copyright (C) 2019 by The American Association for Thoracic Surgery

https://doi.org/10.1016/j.jtcvs.2019.10.024
}

In this issue of the Journal, Paleiron and colleagues ${ }^{1}$ have presented a multi-institutional randomized, controlled trial evaluating the role of preoperative noninvasive ventilation in the days preceding pulmonary resection and its subsequent impact on surgical outcomes. The intended study design is well organized and purposeful, and Paleiron and colleagues $^{1}$ have been very honest in their reporting. Despite these attributes, the study is limited by poor compliance in the noninvasive ventilation group, which is problematic in drawing conclusions. Although this investigation ultimately resulted in a negative result, its foundation and purpose convey an ideology that is important to our thoracic surgical community. This study, along with a rapidly growing breadth of literature in this realm, supports a philosophy of surgical prehabilitation, not only for the purposes of surgical benchmarks but, more importantly, for the success and health of our patients in the broader sense.

Efforts directed toward optimization of the patient's condition in advance of surgery are increasingly prevalent, and this topic is central to several ongoing management strategies and investigational efforts. ${ }^{2}$ Although prevention has traditionally fallen into the domain of primary care fields, it has more recently become integrated into surgical practice, led by such endeavors as enhanced recovery protocols and Strong for Surgery, a quality initiative introduced by the American College of Surgeons. ${ }^{3}$ Although perhaps Paleiron and colleagues ${ }^{1}$ were not able to demonstrate results to support such an endeavor in this instance, this novel work highlights important efforts in a burgeoning field and furthermore should inspire similar investigations to determine the most feasible and achievable manner by which our thoracic surgical community can improve patient health before surgical insult.

Paleiron and colleagues ${ }^{1}$ are among a cohort of investigators seeking to develop protocols for the purpose of respiratory prehabilitation in advance of lung cancer surgery, with unfortunately modest results thus far. ${ }^{4-6}$ Whereas earlier

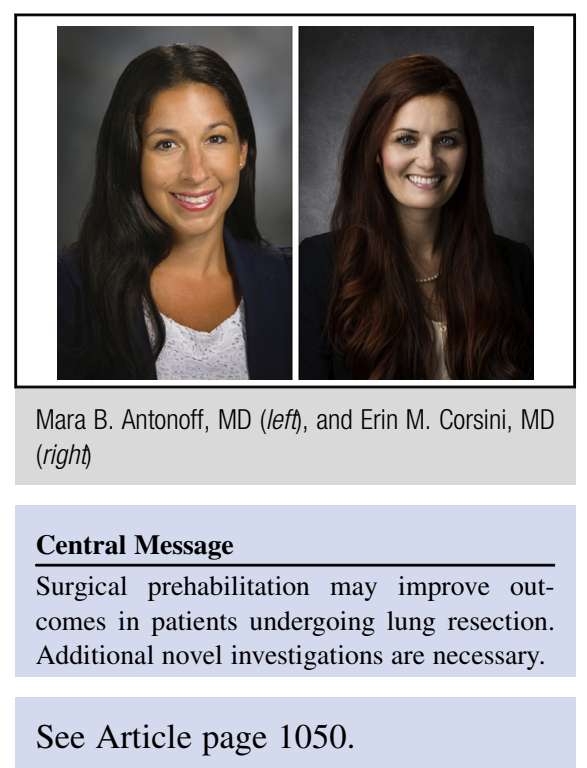

efforts in this area aimed to explore nutritional optimization and smoking cessation programs as targets, more contemporary approaches have attempted to improve ventilatory function and efficiency to reduce postoperative pulmonary complications. As our focus shifts toward proactive, rather than reactive, compensatory measures to improve lung function, novel concepts and methods are required to overcome the expected difficulties with patient motivation and compliance, as has been repeatedly demonstrated with smoking cessation efforts, perhaps one of the earliest cornerstones of surgical prehabilitation. ${ }^{7}$ An appreciation for the approaches, results, and limitations of previous innovative, if guarded, studies will help to build on previously explored techniques to identify those which may be optimally suited for our lung cancer population. Ultimately, although successful surgical prehabilitation is still a work in progress, it carries the potential to serve as the next big breakthrough in optimizing outcomes after lung cancer surgery even further.

\section{References}

1. Paleiron N, Grassin F, Lancelin C, Tromeur C, Margery J, Natale C, et al. Assessment of preoperative noninvasive ventilation before lung cancer surgery: the preOVNI randomized controlled study. J Thorac Cardiovasc Surg. 2020;160: 1050-9.e3

2. Stokes SM, Wakeam E, Antonoff MB, Backhus LM, Meguid RA, Odell D, et al. Optimizing health before elective thoracic surgery: systematic review of 
modifiable risk factors and opportunities for health services research. $J$ Thorac Dis. 2019;11(Suppl 4):S537-54.

3. American College of Surgeons. Strong for Surgery, American College of Surgeons. Available at: https://www.facs.org/quality-programs/strong-for-surgery. Accessed October 5, 2019.

4. Gravier FE, Bonnevie T, Boujibar F, Médrinal C, Prieur G, Combret Y, et al. Effect of prehabilitation on ventilatory efficiency in non-small cell lung cancer patients: a cohort study. J Thorac Cardiovasc Surg. 2019;157: 2504-12.e1.
5. Ben Ali W, Liberman M, Perrault LP. Commentary: prehabilitation for increasing ventilatory efficiency before lung resection: amazing concept, but we're not there yet! J Thorac Cardiovasc Surg. 2019;157:2513-4.

6. Liu Z, Qiu T, Pei L, Zhang Y, Xu L, Cui Y, et al. Two-week multimodal prehabilitation program improves perioperative functional capability in patients undergoing thoracoscopic lobectomy for lung cancer: a randomized controlled trial. Anesth Analg. July 23, 2019 [Epub ahead of print].

7. Varga JT. Smoking and pulmonary complications: respiratory prehabilitation. $J$ Thorac Dis. 2019;11(Suppl 5):S639-44. 